\title{
A IMAGEM POÉTICA: ENTRE O MATERIAL E O IMATERIAL
}

\section{THE POETIC IMAGE: BETWEEN THE MATERIAL AND THE IMMATERIAL}

\begin{abstract}
Adalberto Müller ${ }^{1}$
RESUMO: Entendendo a imagem poética para além do âmbito exclusivo da poesia escrita, e manifestando-se em várias configuraçōes materiais (literatura, cinema, cançấo, artes visuais e da cena, e, também, mas năo sempre, na poesia), queremos pensar a sua manifestaçâo como processo que oscila entre a materialidade e a imaterialidade.

Palavras-chave: Imagem poética; materialidade; processo.

ABSTRACT: Understanding the poetic image beyond the exclusive space of written poetry, as it happens in a diversity of media (literature, cinema, pop song, visual arts, and sometimes in poetry itself, but not always), our aim here is to think its manifestation as process that oscillates between materiality and immateriality.
\end{abstract}

Keywords: Poetic image; materiality; process.

As reflexôes que apresento aqui² resultam da convergência de dois caminhos. Por um lado, uma pesquisa envolvendo literatura e cinema, à qual me dediquei nos últimos dez anos, e que me levou a pensar a relaçâo entre cinema e poesia, e processos de adaptaçăo e de intermedialidade. Por outro lado, o trabalho de traduçăo da poesia completa de Emily Dickinson para o português, que venho realizando há três anos. Aparentemente, trata-se de dois trabalhos desconexos. Pois, na relaçăo entre cinema e literatura, o interesse maior estaria na materialidade, ou na relaçâo entre as mídias, enquanto que, na lida com Emily Dickinson, a atençăo recairia sobre o aparentemente "imaterial" da traduçấo e da poesia, que parecem ser muito mais atividades "do espírito" do que uma lida com a matéria bruta dos meios.

No entanto, reconheço que, a posteriori, os caminhos se encontram, para, talvez novamente se bifurcarem. Na relaçâo entre literatura e cinema, busquei explicitar que a atençấo maior deveria ser dada à mídia, e procurei mostrar como se dá a relaçâo entre poesia e mídia, especialmente no caso de autores como Pasolini, Glauber Rocha ou Orson Welles. Como procurei demonstrar em Linhas imaginárias (2012), cujo subtítulo é "poesia, mídia e cinema"; e em Orson Welles: banda de um homem só (2015), esses poetas-cineastas-performers praticaram a intermedialiade antes mesmo que ela fosse definida pela teoria alemá (MÜLLER, 2010), e, depois, pela teoria

Professor de Teoria da Literatura da UFF.

Trabalho apresentado no Congresso Internacional da ABES, em Simpósio organizado por Alex Martoni. 
canadense-americana (GAUDREAULT 1999; CLÜVER 2008), cruzaram as fronteiras tecnológicas, e produziram obras que questionam o establishment acadêmico das especificidades disciplinares.

Pasolini escreveu poemas com a caneta e com a câmera, ao mesmo tempo que refletiu teoricamente sobre semiologia e sobre o papel da arte na era pós-industrial. Pasolini defendia, em última instância, que a questâo năo era tanto poetizar o cinema, mas poetizar a própria indústria, ou seja, transformar o regime capitalista a ponto de torná-lo poético, isto é, humano. Glauber Rocha propunha, através de uma simbiose da poesia e do cinema, e de uma compreensăo profunda da relaçăo necessária entre tecnologia e arte, politizar a poesia e poetizar a política, ao mesmo tempo, mesmo sabendo que essa tentativa poderia levar ao fracasso. Fracasso que levou, e ainda leva, os intelectuais brasileiros a o julgarem como figura exótica, estrangeira, descontrolada, alienada e irascível (SANTIAGO, 2017); ${ }^{3}$ Terra em transe é o testemunho poético e criativo desse fracasso, que é também o fracasso dos regimes totalitários dos países subdesenvolvidos, sempre oscilando entre o populismo caudilho e o reacionarismo conservador (com o apoio de uma intelligentsia festiva, claro). 0 fracasso do poeta de Terra em transe é a alegoria do fracasso de um país, que ainda náo se encontrou. Orson Welles, por fim, năo apenas leu e adaptou o Dom Quixote, mas transformou-se num Quixote dentro do cinema, lutando para devolver ao cinema o seu caráter mágico e transformador, a despeito de ser americano, ou seja, de viver em um país em que o capitalismo é real, e fundamentalmente selvagem.

Esses três autores, na sua prática criativa, estavam preocupados nâo apenas em fazer imagens, mas criar imagens. Foram homens de seu século, o século XX, um século dominado por aquilo que Vilém Flusser (1983) chamou de imagens técnicas (ou tecnoimagens). As imagens técnicas apenas se parecem com as imagens arcaicas ou com as imagens produzidas até o advento da fotografia. Mas elas já nâo mantêm com a realidade nem uma relaçâo mágica, nem uma relaçăo de representaçăo mimética. As tecnoimagens sâo produto de um texto (e de um cálculo) alfanumérico. Elas já nascem codificadas, programadas, e fazem parte de um mundo em que tudo vai sendo codificado e programado (do código genético dos alimentos às imposiçôes atuais das agências de fomento para os Programas de Pós-Graduaçâo, baseadas na ideia numérica de produtividade).

Nesse "mundo codificado", autores como Pasolini, Glauber e Welles tentaram contrapor as imagens técnicas às imagens poéticas, ou melhor, tentaram produzir imagens poéticas dentro do mesmo aparato que foi feito para produzir (e produz ainda) meramente imagens técnicas. Pasolini chamou isso de cinema di poesia; Glauber, de estética da fome; Welles, de filme-ensaio, ou de magia, simplesmente. Em todo caso, o que importa na obra deles já năo é a imagem apenas, a mera imagem, mas o que eu chamei de imagem sob a imagem. Tal como nos anagramas de Saussure, a imagem sob a imagem remete, de alguma forma, a uma outra imagem, mais arcaica, mais essencial, e,

Salvo engano, sob o pretexto de salvaguardar a obra máxima de Guimarâes Rosa da incompreensâo dos (ou da incompatibilidade com os) seus contemporâneos, Santiago lança um desnecessário ataque à postura política de Glauber, que até pode ter sido equivocada (e acredito que foi), mas que năo deveria ser analisada a partir de episódios de sua vida, sem que viesse à tona também o caráter transgressor, e absolutamente contemporâneo do Grande Sertāo, em termos estéticos, de sua obra cinematográfica. De resto, se fossemos julgar o Grande Sertâo a partir da pessoa de Rosa, seria fácil cair no mesmo tipo de ataque. 
por isso mesmo, capaz de conciliar o terror e a piedade, ou de revelar os vários regimes de falsidade que sustentam o que se entende por verdade, ou realidade (como Welles faz em F For Fake). É assim que Pasolini deixa entrever a palestina contemporânea, faminta e pré-industrial, por trás da história de Jesus em O Evangelho Segundo Sáo Mateus, do mesmo modo que deixa entrever a pobreza na periferia da Roma capitalista. É assim que Glauber, usando a tecnologia "de ponta" do cinema, que é a menina dos olhos da gigantesca indústria do entretenimento, inverte e subverte os termos da produçáo, fazendo o aparato "empobrecer", fazendo a câmera "ter fome", para mostrar que a miséria maior está em quem vê, mas nâo quer ver, a fome. É assim que Welles faz o seu Dom Quixote ir ao cinema, e numa genial traduçáo do episódio do marionetista cervantino, faz com que o cavaleiro andante ataque a própria tela de cinema, rasgando-a, e mostrando o vazio que se oculta sob a superfície das imagens superficiais de Hollywood.

Como procurei mostrar, de vários modos, nos referidos livros e ensaios que publiquei, Pasolini, Glauber e Welles (sem esquecer de Jean Cocteau, de Andrei Tarkovski, e de tantos outros), foram antes poetas que cineastas. A funçăo do cineasta já está definida pela indústria: fazer imagens. $O$ cineasta pode inclusive fazer imagens excelentes, inesquecíveis, tocantes. O poeta, ao contrário, é um criador de imagens (eikonopoietés, como define Aristóteles); a imagem que ele cria está além da superfície: ela flutua entre o material e o imaterial, entre a realidade (referencial) e a imaginaçăo (do espectador), ela é, ao mesmo tempo, imagem e miragem.

Ora, no trabalho de ler, interpretar e traduzir a poesia de Emily Dickinson (os 1789 poemas), tenho me deparado com um problema análogo ao da minha pesquisa sobre (e sob) as imagens. Na minha prática de traduçâo - que evidentemente está embasada em uma teoria da traduçấo -, năo se trata apenas de tentar resolver problemas de letra e espírito, de forma e conteúdo, de estética e semântica, de forma e significaçăo, de conotaçăo e denotaçăo.

Normalmente, a crítica da traduçâo clássica gira em torno dessas antinomias: de um lado estăo o sentido, a significaçấo, o espírito; de outro, a forma, a especificidade de cada língua, a letra. Assim, a traduçâo sempre é acusada de ignorar o aspecto "sensível" (a letra) e buscar traduzir o lado "inteligível" (o espírito), e, por isso mesmo, seria sempre deficitária, menor, menos interessante. Ou entăo, quando ressalta o aspecto sensível, quando ousa investir no aspecto formal, é acusada de traiçâo e de infidelidade (os franceses as chamavam de "belles infidèles".

Minha posiçăo teórica, quanto a isso, segue dois princípios básicos. Primeiro, que as diferenças entre as línguas sempre vâo demandar da traduçăo um certo nível de traiçăo, de infidelidade, pois cada língua representa uma certa visăo de mundo específica sobre as coisas. Segundo, que em se tratando de textos poéticos ou textos em que o investimento "retórico" é grande (estou pensando em Paul de Man), como no caso da filosofia de Nietzsche ou da psicanálise lacaniana, nâo há como traduzir apenas o conteúdo, pois a forma já é parte do conteúdo e o conteúdo da forma. Conteúdo e forma sofreram, nesse caso, uma Aufhebung, para usar um termo hegeliano. Em outros termos, em textos poéticos, a traduçâo "literal" năo é possível, e, ainda que seja possível, ela, de algum modo, falseia e trai, mesmo que pretenda ser fiel, ou manter um "certo nível" de fidelidade (como quer Paulo Henriques Britto). 
Vejamos um caso, o poema F314B, de Emily Dickinson, e algumas das suas traduçôes (ver anexo).

\author{
"Hope" is the thing with feathers - \\ That perches in the soul - \\ And sings the tune without the words- \\ And never stops - at all - \\ And sweetest - in the Gale - is heard - \\ And sore must be the storm - \\ That could abash the little Bird \\ That kept so many warm - \\ I've heard it in the chillest land - \\ And on the strangest Sea- \\ Yet - never - in Extremity, \\ It asked a crumb - of me.
}

(Fascicle 13, Winter, 1861)

Náo me deterei muito em questôes de ritmo, apenas queria lembrar que, como em 90\% de seus poemas, Emily Dickinson usa o common meter (alternado trímetros e tetrâmetros jâmbicos) e rimas imperfeitas nos versos pares apenas (algumas rimas bem sutis, como "soul" e "all", só ouvida na pronúncia da Nova Inglaterra, de onde ela era). Ao contrário das demais traduçōes, procurei manter esse esquema rítmico e rímico, sem descuidar, no entanto, da relaçăo entre pensamento (as ideias do poema) e as imagens.

A imagem central do poema é um símile, ou uma metáfora desenvolvida, figura muito usada na literatura desde Homero. Aqui, a esperança é uma espécie pássaro cantando sempre; seu canto, que aquece, só para com a tempestade. A poeta já a viu em todo lugar, mas ela nunca lhe pediu nenhuma migalha - isto é, a poeta nunca deu trela à esperança. Essa imagem, na primeira estrofe, faz lembrar a do "Corvo", de Edgar Alan Poe, embora Emily Dickinson o detestasse (ela o achava excessivo e repulsivo, como a Whitman). É a essa imagem que o tradutor tem que se aferrar, embora a cada verso e a cada estrofe ela esteja prenhe de detalhes. E, como dizia Flaubert, "le bon Dieu est dans le détail."

Por exemplo, "thing of feathers", que lembra o famoso verso de Keats ("A thing of Beauty is a Joy forever"), é essencial manter a "coisa", pois ela serve para manter a imagem do pássaro (ou da pássara) ${ }^{4}$ em suspenso. Ao mesmo tempo, é uma coisa, nâo é um "Ser", como na tradução de José Lira. Evitei também traduzir "feathers" por "penas" para nâo criar uma confusâo com penas no sentido de "sofrimentos", mas também porque a imagem de um pássaro estranho e raro me parece combinar melhor com uma "coisa com plumas". É importante também ser mais preciso quanto à imagem criada em torno do verbo "sing": nâo se trata de "soltar um canto", mas sim, de "cantar uma melodia", embora melodia seja uma palavra mais limitada semanticamente que "tune",

4 Essa forma, no gênero feminino, aparece em Joăo Cabral. 
e, além disso, mais extensa (o equilíbrio rítmico desse verso, um tetrâmetro jâmbico perfeito, depende das aliteraçóes e das palavras monossilábicas ("and sings the tune without the words").

Na segunda estrofe, temos uma progressăo de imagens: ventania seguida de tempestade e um "pequeno pássaro" cantando. É importante manter a ideia, uma condiçâo expressa pela combinaçāo de "and", "must" e "could" (que José Lira abafou): o pássaro da esperança sempre canta, e somente se houver uma tempestade, ele deixará de nos acalentar, de nos dar esperanças. Preferi usar "Passarinha" no feminino porque se trata de uma personificaçấo da Esperança, que nâo concordaria com o masculino, como em José Lira. Essa Passarinha é justamente uma imagem que oscila entre o abstrato e o concreto, entre o material e o imaterial. É uma imagem sob a imagem. No fundo, ela quer dizer, como se diz em Português, que "a esperança é a última que morre" (em inglês se diz "hope never fails").

Por fim, as imagens da última estrofe sâo uma intensificaçâo das anteriores: a poeta, que agora se identifica pelo pronome, diz ter visto a esperança nos lugares mais impossíveis (isto é, ela está em todos os lugares), como "chillest lands" e "strangest Sea"; no entanto, ela afirma, a esperança (que é uma avezinha) nunca lhe pediu uma migalha sequer. Trata-se de uma litote: ela diz o que quer dizer (nâo tenho esperanças) pelo avesso (a esperança nunca me ofereceu nada). Aqui é fundamental manter a relaçâo imagética entre pássaro e migalha (de modo algum se poderia confundir migalha com pâo!). Por fim, há que se considerar "Extremity": a traduçâo mais adequada seria "em situaçôes extremas", isto é, de na dor, na miséria, na angústia. Năo se trata de "Extremidade", palavra longa e pesada, pois extremidade é uma noçâo mais espacial. É antes o extremo de uma situaçăo, no tempo-espaço. Emily Dickinson tinha predileçăo pelo uso de palavras de origem latina quando queria exprimir ideias mais abstratas. Se quisesse ser mais concreta, ela usaria "In Woe" ou "In Grief".

Desse modo, traduzir é sempre e antes de mais nada um trabalho de reconfiguraçăo. Re-configurar significa, literalmente, a partir de uma configuraçấo (de uma imagem) em um texto escrito numa língua estrangeira (ou em outra linguagem), criar uma figura análoga, uma imagem análoga, na sua ou em outra língua ou linguagem. Mais do que um ato de recriaçăo, ou transcriaçăo, o trabalho do tradutor é um trabalho de reconfigurar imagens, sons e ideias em outra língua. Desse modo, o tradutor tem que assumir a traiçâo na mesma medida em que assume a fidelidade. 0 tradutor é um mediador. E, ao mesmo tempo, um encantador (de serpentes).

Vale lembrar que a criaçâo de imagens nâo é atributo exclusivo dos poetas ou dos artistas. Além de estarmos num mundo de imagens (tudo o que vemos é imagem, mesmo as coisas que imaginamos mentalmente), além de nos relacionarmos com imagens antes de traduzi-las em palavras (pois o olho é mais rápido), sempre que falamos ou gesticulamos, ou damos a entender, estamos articulando imagens. Se eu digo a vocês: o mar hoje está "bravo", vocês imaginam o "bravo" antes de tomar uma decisăo de ir ou náo entrar no mar. Um amante de Homero, como eu, pensaria em Poseidon movendo as ondas. Claro que a linguagem conceitual e técnica tende a afastar-se desse aspecto figurativo, em linguagem técnica se dirá "o mar está perigoso hoje", ou "o mar está inadequado ao banho devido à força da maré" etc. Um poeta, como Paulinho da Viola, diria (citando o seu pai): "o mar năo tem cabelos / que a gente possa agarrar". Se, no caso da 
linguagem técnica ou conceitual, o problema da imagem é menor (embora ele exista), no caso da linguagem cotidiana e da linguagem poética, as imagens sempre cumprem um papel importante na comunicaçấo. As imagens săo atalhos. Ou elevadores. Essa imagem é de Francis Ponge, ele imaginou, no seu Malherbe, que a poesia é uma espécie de elevador para nos levar mais rápido a níveis elevados de conhecimento.

Mas é no caso da poesia e dos usos poéticos da linguagem (na literatura, nas artes), que as imagens săo imprescindíveis. Nâo que năo haja poesia, ou arte, sem imagens. Pode ser que, em certos poemas ou em certas obras de arte, a imagem ceda ao pensamento, ou ao ritmo, ou simplesmente às coisas pura e simplesmente, às coisas "como elas sâo", sem artifícios de linguagem. Mas eu diria que as coisas sempre evocam imagens. As coisas sempre precisam ser sentidas, percebidas, e ao se sentirem, ao se perceberem, săo como as imagens no espelho: signos, reflexos, ficçōes. Lembro-me dos poemas de Adília Lopes, tăo centrados na fala, tăo aparentemente limpos de metáforas e de imagens (ao contrário de sua conterrânea contemporânea, a Fiama Hasse Paes Brandăo, tăo densa em imagens e tấo intensa). Mas aqui e ali, em Adília Lopes, as imagens a tomam de assalto, e, consequentemente, nos dăo um susto. Como neste poeminha, para encerrar este ensaio:

Deus é um boomerang

e eu sou sua filha pródiga. 


\section{Referências Bibliográficas}

CLÜVER, Claus. Intermedialidade e Estudos Interartes. In: NITRINI, Sandra; PEREIRA, et alli (org.). Literatura, artes, saberes. Săo Paulo, SP: Editora Hucitec, 2008.

DICKINSON, Emily. Poems as She Preserved Them. Ed. Cristanne Miller. Cambridge: Belknapp/Harvard University Press, 2016.

FLUSSER, Vilém. Pós-História. Sāo Paulo: Hucitec, 1983.

GAUDREAULT, André. Littérature et Cinéma. Montréal: Nota Bene, 1999.

MÜLLER, Adalberto. Linhas Imaginárias: poesia, mídia, cinema. Porto Alegre: Sulina, 2012.

. Orson Welles: banda de um homem só. Rio de Janeiro: Azougue Editorial, 2015.

SANTIAGO, Silviano. Genealogia da Ferocidade. Recife: CEPE, 2017.

ANEXO: O POEMA DE EMILY DICKISON E SUAS TRADUÇŌES

"Hope" is the thing with feathers - *

[F314B; J254]

"Esperança" é a coisa com plumas -

Que na alma se aninha-

Seu canto é sem palavras -

Sempre a mesma-ladainha-

Soa bem - na ventania -

E só a forte tormenta -

Há de calar a Passarinha

Que a tantos acalenta -

Ouvi-a na terra mais fria-

E nos Mares sem fim -

Nem em situaçóes extremas

Pediu migalhas - pra Mim.

(Trad. Adalberto Müller)

\footnotetext{
A "Esperança" é a coisa com penas-

Que se empoleira na alma-

E canta melodia sem palavras -

E nunca-nunca para-

E mesmo em Vendaval - doce - é ouvida -

E a tempestade seria mais cruel-

Para abater essa pequena Ave

Que a tantos aqueceu -

Ouvi-a pela terra mais gelada-

No mais estranho Mar -
} 
Mas nunca, em Extremidade, me pediu

A mim - uma migalha.

(Trad. Ana Luísa Amaral)

A "Esperança" é o ser de plumasQue pousa em nossa Alma E solta um canto sem palavras E nâo para - jamais -

E ao vendaval - fala mais doce E é o temporal mais crespo Que há de calar o Passarinho Que a tantos aqueceu -

Ouvi-o nas mais frias terras Nos Mares mais estranhos Mas nunca, na maior Miséria, Me pediu - do meu pão.

(Trad. José Lira) 